\title{
Exploring the Factors Affecting the Use of Kiasu Tactics
}

\author{
Eric G. Kirby \\ Susan L. Kirby \\ James D. Bell \\ Curt Schafer \\ Texas State University
}

\begin{abstract}
Kiasuism is an excessive form of competitiveness in which an individual tries to get the most out of every interaction. It manifests itself in the form of positive and negative tactics. This study explores the factors affecting the use of kiasu tactics. Maximization, conscientiousness, and perceptions of distributive justice are examined using multiple regression analysis. Maximizers are far more likely to engage in both kiasu positive and kiasu negative tactics than are satisficers. When people perceive that outputs are distributed fairly, they are more likely to engage in kiasu positive tactics. Conscientiousness did not have a significant effect.
\end{abstract}

\section{Theoretical Development and Hypotheses}

\section{$\underline{\text { Kiasuism }}$}

Competitiveness is an integral part of U.S. culture that is related to success. However, when a person's competitive spirit transforms into an extreme desire to win, it can have negative effects as well. A competitive spirit drives people to excel, but can also make them overly aggressive (Bing, 1999).

In Asian societies this excessive competitiveness is called "kiasuism" (pronounced KEYah-sue-ism). Kiasuism is an "obsessive concern with getting the most out of every transaction and a desire to get ahead of others" (Hwang, Ang, \& Francesco, 2002, p. 75). Kiasuism can lead to both positive and negative outcomes. "The kiasu person is selfish. He takes more than he needs... He is inconsiderate. He is greedy. And he is definitely obnoxious" (Leo, 1995, p. 18). Simultaneously, kiasuism has positive benefits. The kiasu person often excels because he or she wants to win. People employing kiasuism scan the environment for opportunities and take quick advantage of them (Leo, 1995). For a 'high kiasu' individual, every action is designed to ensure that the person or their beneficiary gains an advantage. Kiasuism is a factor in the culture of Singapore, but it is not unique to that country. It has also been observed in Hong Kong (Chua, 1989), Australia (Ho, Ang, \& Ng, 1998), and the United States (Kirby \& Ross, 2007).

As noted, kiasuism is a form of competitiveness and has an associated set of tactics designed to achieve a desired end (Hwang, 2003). If the use of these tactics becomes obsessive and an end-unto-itself, kiasuism may be seen as a form of 
hypercompetitiveness. Hypercompetitiveness is an irrational personality attribute where the desire to win becomes an end in itself (Bing, 1999). A hypercompetitive individual sees everything as a competition in which he or she must win, even if this competitive spirit is destructive or counterproductive (Horney, 1937).

Although there are conceptual similarities, kiasuism is distinct from hypercompetitiveness. Hypercompetitiveness is seen as a maladaptive behavior (Kohn, 1992) and a neurotic personality attribute (Horney, 1937). A hypercompetitive individual is competing "as a means of maintaining or enhancing feelings of self-worth, with attendant orientations of manipulation, aggressiveness, exploitation, and derogation of others across a myriad of situations" (Ryckman, Libby, van den Borne, Gold, \& Linder, 1997, p. 271). Competition itself becomes the goal. Kiasuism is not seen as a maladaptive behavior; it is a set of conscious behaviors designed to achieve a desired goal (Ho et al., 1998). While the obsessive use of competitive behaviors can become detrimental, kiasuism is a tactic rather than an end onto itself.

Kiasuism is a competitive spirit and an approach to life that manifests itself as specific tactics for achieving goals. The purpose of kiasu tactics is to gain a competitive advantage over others. Kiasu tactics can manifest themselves in a variety of ways. Hwang et al. (2002) identified two distinct classes of kiasu tactics: kiasu-positive and kiasu-negative. The goal of both tactics is to gain a competitive advantage, however they differ in their approach to achieve this outcome.

Kiasu-positive tactics are based on putting in additional effort to increase one's performance. For example, in an academic setting, kiasu-positive tactics could include studying longer and more diligently, asking questions during a professor's office hours, and reading supplemental materials beyond what is required (Hwang et al., 2002). Kiasu-positive tactics cause students to put additional work into their classes, a tactic related to improved academic performance. Such students are also likely to be seen by other students as valuable resources for any group-based class projects. Prior research has supported this positive relationship between the use of kiasu-positive tactics and academic performance (Kirby \& Ross, 2007).

Kiasu-negative tactics involve the use of guile, deceit, and selfishness to gain competitive advantage. Illustrations of this tactic in an academic setting could include pretending to be disinterested in a class in front of other students, claiming not to have taken good notes when asked to share them, and hiding reference materials in the college library (Hwang et al., 2002). "In general, the kiasu-negative attitude reflected a desire to keep material and knowledge to oneself so that other students would not benefit from them. In doing so, those with more material or knowledge would have an advantage over others" (Hwang et al., 2002, pp. 78-79). While such tactics may make a student unpopular with their peers, they are likely to aid in gaining competitive advantage over fellow students in terms of performance on exams. These relationships between kiasu-negative tactics and outcomes have also been supported by prior research (Kirby \& Ross, 2007). 
Only five studies have examined the construct of kiasuism, and all utilized kiasuism to predict student behaviors (Ho et al., 1998; Hwang et al., 2002; Hwang, 2003; Hwang \& Arbuagh, 2006; Kirby \& Ross, 2007). However, prior research has yet to address what drives a person to engage in kiasu tactics. To develop the nomological net of kiasuism, it is necessary to investigate how it is relates to other constructs (Chronbach \& Meehl, 1955). In this case, we are interested in exploring what traits lead a person toward the use of kiasu tactics. Specifically, we investigate the effects of maximization, conscientiousness, and distributive fairness.

\section{Maximization}

Maximization is the term used to describe the trait whereby people seek to optimize their decisions. Maximizers are assumed to evaluate all decisions and behavioral alternatives before selecting the optimal solution. This underlies the traditional notion of rational decision making. More than fifty years ago, Herbert Simon (1955) proposed the idea that this was a false assumption of how people make decisions. According to Simon, people do not seek an optimal solution due to limits in human cognition; they look for an alternative that is 'good enough.' That is, they set a minimum acceptable threshold and any outcomes that meet this threshold are deemed to be adequate (Schwartz, Ward, Monterosso, Lyubomirsky, White, \& Lehman, 2002). Simon (1955) argues that people satisfice rather than maximize when making a decision and/or choosing a course of action.

Schwartz et al. (2002) argued that individuals vary in their propensity toward maximization or satisficing. Some people tend to maximize, while others tend to satisfice. This is typically operationalized of as a continuum ranging from extremes on both ends. Satisficers tend to engage in behaviors that are 'good enough' to achieve satisfactory outcomes. They are not particularly concerned with their success relative to others (Schwartz et al., 2002). Maximizers, on the other hand, tend toward behaviors that lead to optimal outcomes. Maximizers are quite concerned with their relative success to others and, thus, seek to outperform their peers (Schwartz et al., 2002).

Therefore, we predict that a person's propensity toward maximization or satisficing will have an impact on their kiasuism as it is related to gaining competitive advantage over others. Maximizers are going to seek ways to gain competitive advantages over others, while satisficers are less likely to do so. In particular, we make the following hypotheses with respect to maximizations effects on kiasu tactics:

Hypothesis 1a: There will be positive relationship between maximization and the use of kiasu-positive tactics.

Hypothesis 1b: There will be positive relationship between maximization and the use of kiasu-negative tactics. 


\section{$\underline{\text { Conscientiousness }}$}

Conscientiousness is the trait of being careful and of meeting one's commitments and obligations. It is characterized by competence, order, dutifulness, achievement-striving, self-discipline, and deliberation (Costa \& McCrae, 1992). Conscientiousness is consistently shown to positively affect workplace performance (Salgado, 1997). People that are conscientious are typically success driven, hard working, and have a high need for achievement (Mount \& Barrick, 1995). People with lower conscientiousness tend to be 'laid back,' less goal-oriented, and less driven by success (Mount $\&$ Barrick, 1995).

Recent studies have found significant positive relationships between conscientiousness and competitiveness. Ross, Rausch, and Canada (2003) found that competitive attitudes were significantly positively affected by the achievement-striving component of conscientiousness. Another recent study of online game players found that players exhibiting high levels of conscientiousness had an advantage in interpersonal competition (Teng, 2008).

Therefore, we predict that a person's conscientiousness will affect their use of kiasu tactics. Highly conscientiousness people will likely engage in behaviors that help them achieve success. Specifically, we hypothesize:

Hypothesis 2a: There will be positive relationship between conscientiousness and the use of kiasu-positive tactics. Hypothesis $2 \mathrm{~b}$ : There will be positive relationship between conscientiousness and the use of kiasu-negative tactics.

\section{Distributive Fairness}

Justice theory attempts to explain and describe the role of fairness in the workplace. Organizational justice is often used to explore individual attitudes toward perceived fairness of outcomes and procedures in the context of organizations. The process through which allocation decisions are made forms the basis of perceived procedural justice. Individuals are concerned with the perceived fairness of allocation procedures regardless of the perceived fairness of decision outcomes (Folger \& Konovsky, 1989; McFarlin \& Sweeney, 1992). Leventhal (1980) emphasizes that a fair allocation process will be consistently applied, free from bias, reflect accurate information, represent accepted values, allow for correctability, and be applied in an ethical manner. The perceived fairness of one's outcomes form the core of distributive justice (Greenberg, 1990).

Empirical research suggest that both justice dimensions are related to attitudes toward a variety of psychological constructs, such as satisfaction with leaders (Tyler \& Caine, 1981), adaptation to layoffs (Brockner, Grover, Need, DeWitt, \& O'Malley, 1987), reactions to performance appraisal (Greenberg, 1986), and attitudes toward corporate drug testing programs (Tepper, 1994). Procedural and distributive justice provide a theoretical framework for an exploration of the impact of why people engage in kiasu 
tactics. We believe that distributive justice will have a greater impact on the use of kiasu tactics since it is concerned with outcome distribution.

According to the theory of distributive justice, people will be satisfied with the outcomes they receive if they perceive that they are bestowed based on contributions (Greenberg, 1990). Therefore, we hypothesize that people who perceive the distribution of outcomes to be fair will be more likely to engage in kiasu tactics based on hard work. Specifically, we hypothesize:

Hypothesis 3a: There will be positive relationship between the use of kiasu-positive tactics and the importance of distributive justice.

People who value distributive fairness are unlikely to approve of an unjust distribution of outcomes even if they benefit (Greenberg, 1990). Such people are, therefore, unlikely to engage in tactics based on deceit and guile to gain extra rewards. Therefore, we hypothesize:

Hypothesis $3 \mathrm{~b}$ : There will be negative relationship between the use of kiasu-negative tactics and the importance of distributive justice.

\section{Methods}

\section{Sample and Procedures}

To test the hypotheses, 319 undergraduate students from a large southwestern university were recruited for participation in this study. All subjects were enrolled in management classes taught by two of the authors, and all data were gathered using questionnaires administered at the end of the semester. In the end, 299 usable surveys were obtained from the students, yielding an overall response rate of 94 percent. The average age of the respondents was 22 years old, 66 percent were male, and 84 percent were majoring in some form of business (13\% accounting, $2 \% \mathrm{CIS}, 1 \%$ economics, $12 \%$ finance, $37 \%$ management, and $19 \%$ marketing). T-tests on all of the demographic and academic major variables revealed no significant differences in the survey results between the two professors' courses; therefore, all surveys were compiled into a single dataset.

Actions were taken to lessen some of the issues surrounding common method variance. Participation was voluntary and student who elected not to complete the survey were given an equally attractive alternative exercise. Approval to conduct the survey was obtained from the Institutional Review Board, and participants were assured their responses would be kept confidential. Following the suggestions of Nunnally and Bernstein (1994), a concerted effort was made to avoid implying one response was preferable over another; all responses were of equal effort to the respondents; close attention was paid to the details of the item wording; items were used that were less subject to bias; and clear instructions were provided. In addition, reverse-scored items 
were included in the survey questionnaires to help ameliorate common method variance (Kline, Sulsky, \& Rever-Moriyama, 2000).

\section{Dependent Measures}

Kiasu tactics were operationalized with two measures: kiasu-positive tactics and kiasunegative tactics.

\section{$\underline{\text { Kiasu-Positive Tactics }}$}

Kiasu-positive tactics are kiasu behaviors that manifest themselves through diligence and hard work to excel (Chua, 1989). Education-specific kiasu-positive tactics were operationalized using the three items developed by Hwang et al. (2002), with a reported reliability of .85 . Sample items include "I read beyond my assigned readings" and "I do extra research to improve my coursework." The items were scored on a 7-point Likerttype scale $(1=$ never to $7=$ all the time $)$ and averaged to arrive at a single measure.

\section{$\underline{\text { Kiasu-Negative Tactics }}$}

Kiasu-negative tactics are kiasu behaviors that manifest themselves through selfish behaviors and guile (Kagda, 1993). Education-specific kiasu-negative tactics were operationalized using the three items developed by Hwang et al. (2002), with a reported reliability of .89. Sample items include "I try not to let others know the right answer" and "I do not share useful information with others." The items were scored on a 7-point Likert-type scale $(1=$ never to $7=$ all the time $)$ and averaged to arrive at a single measure.

\section{$\underline{\text { Independent Measures }}$}

As previously hypothesized, this study examines the effects of conscientiousness, maximization, and equity sensitivity on kiasuism.

\section{$\underline{\text { Conscientiousness }}$}

The predictor measure of conscientiousness was measured using the Factor III items from the 50-item International Personality Item Pool (Goldberg et al., 2006). This is a 7point Likert scale assessing one's conscientiousness. Sample items are "I am always prepared" and "I shirk my duties." Responses are scaled from 1 (very inaccurate) to 7 (very accurate). Four of the items are reverse-scored, then they are all summed to arrive at an individual's conscientiousness score, with lower scores reflecting greater conscientiousness. The scale has a reported reliability of 0.75 (IPIP, 2008). 


\section{$\underline{\text { Maximization }}$}

Maximization was measured using the 13-item Maximization Scale developed by Schwartz et al. (2002). This is a 7-point Likert scale assessing one's tendency to maximize. Sample items are "I never settle for second best" and "No matter how satisfied I am with my job, it's only right for me to be on the lookout for better opportunities." Responses are scaled from 1 (completely disagree) to 7 (completely agree). The items are summed to arrive at an individual's maximization, with higher scores reflecting greater maximization. Schwartz et al. (2002) report a reliability of .71 for the scale.

\section{Distributive Fairness}

Consistent with other studies (Giles, Findley, \& Feild, 1997), distributive fairness was assessed using a distributive justice scale. Distributive justice was measured using the four-item scale developed by Colquitt (2001). This is a 7-point Likert scale assessing one's perception of distributive fairness within a given context. The scale is designed to be slightly modified to fit the testing situation (Colquitt, 2001). Since this study was conducted in an academic setting, the items were written to assess the distribution of grades. Sample items include "My current GPA accurately reflects the effort I have put into my classes," and "My current GPA is justified given my academic performance." Responses are scaled from 1 (completely disagree) to 7 (completely agree). The items are summed to arrive at an individual's overall perceptions of the fairness of the distribution of outcomes in a given context, with higher scores reflecting greater perception of distributive fairness. We calculated a reliability of 0.78 for the scale.

\section{$\underline{\text { Control Measures }}$}

To assess the impact of maximization, conscientiousness, and distributive fairness on the use of kiasu tactics, two control variables were measured: sex and age.

\section{$\underline{\text { Sex }}$}

Prior studies have found differences in competitiveness between men and women (cf., Campbell, 2002). In a recent study, Raviv and Netz (2007) found that men rated competition as an incentive for engaging in activity much more highly than did women. Niederle and Vesterlund (2007) found that women have a greater tendency than men to shy away from competitive situations. Therefore, we control for the effects of sex on kiasuism, with females being coded as 0 and males as 1 .

$\underline{\text { Age }}$

Competitiveness varies as a function of age. Studies have found that older adults value competition less highly than do younger ones (Duda \& Tappe, 1988). In their recent study, Raviv and Netz (2007) found significant differences by age in how important 
individuals rated competition as an incentive in engaging in activity. When conducting research using college students, even small ranges in age can be informative and should be controlled (Morgan \& Kunkel, 2007). Therefore, we control for the effects of age in years on kiasuism.

\section{Results}

\section{$\underline{\text { Descriptives }}$}

Table 1 presents means, standard deviations, and correlation coefficients for the variables under study. Multiple indicators of different facets of the same phenomenon are necessary for improved construct validity, however they are often intercorrelated with one another (Pedhazur \& Schmelkin, 1991). However, an examination of the correlation matrix indicates that all of the correlation coefficients are considerably less than 0.8 in absolute value, a frequently cited and commonly used threshold for the detection of multicollinearity (Kennedy, 2008).

Table 1. Descriptive Statistics and Correlation.

\begin{tabular}{l|rlllllll}
\hline Variable & Mean & s.d. & 1 & 2 & 3 & 4 & 5 & 6 \\
\hline 1. Kiasu Positive & 3.23 & 1.23 & & & & & & \\
2. Kiasu Negative & 1.96 & 1.02 & .03 & & & & & \\
3. Age & 22.40 & 2.93 & $.15^{* *}$ & .01 & & & & \\
4. Sex & 0.66 & 0.47 & .11 & -.02 & .02 & & & \\
5. Maximization & 4.35 & 0.74 & $.14^{*}$ & $.22^{* *}$ & $-.12^{*}$ & -.02 & & \\
6. Conscientiousness & 4.65 & 1.07 & .00 & -.08 & .00 & -.03 & -.02 & \\
7. Distributive & 4.94 & 1.21 & .10 & -.03 & $-.12^{*}$ & $-.21^{* *}$ & .01 & -.04 \\
Fairness & & & & & & & & \\
\hline
\end{tabular}

*significant at $p<.05$

${ }^{* *}$ significant at $p<.01$

Multiple Regression Models

To assess the impact of the independent variables on kiasu tactics while simultaneously holding constant the impact of the other variables, multiple regression analysis was employed. The results of the multiple regression equation testing Hypotheses 1a, 2a, and $3 a$ are shown in Table 2 . The overall model is statistically significant and maximization and distributive fairness account for significant portions of the variance in kiasu-positive tactics. However, conscientiousness does not contribute significantly to the variance in the use of kiasu-positive tactics. Therefore, Hypotheses 1a and $3 a$ are supported, but Hypothesis 2a is not supported. 
Table 2. Results of Multiple Regression Analysis on Kiasu-Positive Tactics

\begin{tabular}{lccl}
\hline Variable & B & s.e. & $\beta$ \\
\hline Constant & -.72 & .87 & \\
Age & .08 & .02 & $.19^{* *}$ \\
Sex & .38 & .15 & $.14^{*}$ \\
Maximization & .25 & .10 & $.15^{\star *}$ \\
Conscientious & .02 & .07 & .02 \\
Distributive & .15 & .06 & $.15^{\star *}$ \\
\hline F-score & & $4.998^{* *}$ & \\
$\mathrm{R}^{2}$ & & .081 & \\
Adjusted $\mathrm{R}^{2}$ & & .065 & \\
\hline
\end{tabular}

*significant at $p<.05$

${ }^{* *}$ significant at $p<.01$

The results of the multiple regression analysis testing Hypotheses $1 \mathrm{~b}, 2 \mathrm{~b}$, and $3 \mathrm{~b}$ are shown in Table 3. They indicate that the overall model is statistically significant and maximization accounts for a significant portion of the variance in kiasu-negative tactics. Therefore, Hypothesis $1 b$ is supported. However, there is no support for Hypothesis $2 b$ that conscientiousness will significantly predict kiasu-negative tactics. There is also no support for Hypothesis $3 \mathrm{~b}$ that distributive fairness will have a significant negative effect on the use of kiasu-negative tactics.

Table 3. Results of Multiple Regression Analysis on Kiasu-Negative Tactics

\begin{tabular}{lrcc}
\hline Variable & \multicolumn{1}{c}{ B } & s.e. & $\beta$ \\
\hline Constant & 1.01 & .74 \\
Age & .01 & .02 & .02 \\
Sex & -.08 & .13 & -.04 \\
Maximization & .32 & .08 & $.23^{* *}$ \\
Conscientious & -.07 & .06 & -.07 \\
Distributive & -.04 & .05 & -.04 \\
\hline F-score & \multicolumn{3}{c}{$3.620^{* *}$} \\
$\mathrm{R}^{2}$ & \multicolumn{3}{c}{.060} \\
Adjusted $\mathrm{R}^{2}$ & \multicolumn{3}{c}{.043} \\
\hline
\end{tabular}

*significant at $p<.05$

${ }^{* *}$ significant at $p<.01$ 


\section{Discussion}

This study set about to investigate individual variables effecting kiasuism. As previously stated, no prior research has explored the underlying factors that impact the use of kiasu tactics. Drawing on other studies, we hypothesized that conscientiousness, maximization, and distributive fairness would impact kiasu behaviors. Analysis determined that maximization had the greatest impact of the three, explaining a significant portion of the variance in both kiasu-positive and kiasu-negative tactics. This is not surprising as maximization is about seeking the best outcomes in a variety of situation. Maximizers optimize all of their actions in order to increase their outcomes. Therefore, maximizers would likely employ any tactics that could yield an improved situation for themselves.

Conscientiousness had no significant effect on the use of kiasu tactics, either positive or negative. This is unexpected given that conscientiousness has consistently been shown as one of the best predictors of success across a wide rage of situations. Given that we were examining factors affecting the employment of kiasu tactics, perhaps these are not the tactics of choice for conscientious individuals. Conscientious individuals honor their commitments and obligations. Kiasu tactics are about going above-and-beyond and putting in extra effort to help yourself or hinder others. As it manifests itself in a college academic setting, conscientious students complete their assignments on time, study for their exams, and attend class regularly. However, due to the structured nature of academic settings students may not feel the need to go above-and-beyond the stated objectives in order to achieve success. Given that there are clear expectations for success in academic settings, merely doing what is expected of them may provide enough of a competitive advantage for them to succeed. Perhaps the results would be different in a more competitive situation, or where extreme and rigorous performance was the norm such as fields like sales or athletics.

Perceptions of distributive fairness had a significant effect on the use of kiasu-positive tactics, but no significant effect on the use of kiasu-negative tactics. It is understandable that people will engage in extra work if they believe their effort will be rewarded by an equitable distribution of rewards. Theory posits that individuals will avoid behaviors of guile if they feel this will undermine the equitable distribution of rewards. This was not confirmed. It is possible that our results are being mitigated by the context in which this study was conducted. We examined college students in an academic setting in which the rewards in question are grades, and these grades are determined on a standard 9080-70-60 percent scale. It is possible that different results would have been achieved under a different grading system or in more competitive situations.

It is also interesting that the control variables of age and sex were significant in the analyses. Both older subjects and men were more likely to engage in kiasu positive tactics than were younger subject and women. We suppose this has to do with the earlier discussions of males being more competitive, however the finding that older subjects engaged in more kiasu positive tactics is puzzling. This may have more to do with generational differences in term of showing initiative and 'going above and beyond' 
(Twenge, 2006) than with difference in competitiveness. In fact, our experience dealing with older 'non-traditional' students is that many of them are anxious about their ability to compete with younger students due to the long gaps in their formal education. The use of kiasu positive tactics may serve as a means of overcompensating for their perceived shortcomings. An interesting future study might focus on students 25 years of age and older.

\section{Limitations and Future Research}

It is clear that the context within which any study is conducted has an impact on the engagement in kiasu behaviors and tactics. We choose to assess the impact of perceptions of distributive justice. It is possible that other fairness variables, such as interpersonal and procedural justice would have an effect. It is also possible that the relationships could be moderated by one's equity sensitivity, which is a person's overall concern with fairness in a given situation. These could all be avenues for future research.

As previously surmised in the discussion, it is likely that the results were impacted by the context within which the study was conducted. In a large public university, students do not compete with one another in the same way employees do in industry. In a classroom, it is possible for all students to excel. However, in a competitive workplace, there may only be one open position for promotion, or a finite amount of money for bonuses. A future study could draw upon our findings to examine the impact in a competitive corporate environment.

Comparative studies across target student populations might yield interesting results as well. Researchers could look at groups such as non-traditional students, honor's students, fraternity and sorority members, international students, and student athletes. All of these groups may differ in terms of their predisposition toward and determinants of use of kiasu tactics.

Given the nature of the survey instruments, there is concern over common method variance. As previously discussed, concerted effort was made to reduce the effects. In any type of self-report survey, common method variance cannot be eliminated (Kline et al, 2000). However, careful research design can ameliorate the problem (Spencer \& Brannick, 1995).

In sum, this study provides some preliminary answers to the question of what drives people to engage in kiasu tactics. The results of this study indicate that maximizers are far more likely to engage in both kiasu positive and kiasu negative tactics than are satisficers. Additionally, distributive fairness plays a role. When people perceive that outputs are distributed fairly, they are more likely to engage in kiasu positive tactics than when they do not perceive such distributive fairness. This study has only exposed the proverbial tip of the iceberg, and further research is necessary to better understand how, why, and where kiasuism manifests itself. 


\section{References}

Bing, M. N. (1999). Hypercompetitiveness in academia: Achieving criterion-related validity from item context specificity. Journal of Personality Assessment, 73(1), 80-99.

Brockner, J., Grover, S., Reed, T., DeWitt, R., \& O'Malley, M. (1987). Survivor's reactions to layoffs: We get by with a little help from our friends. Administrative Science Quarterly, 32, 526-541.

Campbell, A. (2002). A mind of her own: The evolutionary psychology of women. Oxford. Oxford University Press.

Chua, C. C. (1989). Kiasuism is not all bad. The Straits Times, June 23, 14.

Colquitt, J. A. (2001). On the dimensionality of organizational justice: A construct validation of a measure. Journal of Applied Psychology, 86, 386-400.

Costa, P. T., \& McCrae, R. R. (1992). NEO PI-R professional manual. Odessa, FL: Psychological Assessment Resources.

Cronbach, L., \& Meehl, P. (1955). Construct validity in psychological tests. Psychological Bulletin, 52(4), 281-302.

Duda, J. L. \& Tappe, M. K. (1988). Predictors of personal investment in exercise among middle age and older adults. Perceptual and Motor Skills, 66, 543-549.

Folger, R., \& Konovsky, M. A. (1989). Effects of distributive and procedural justice on reaching to pay raise decisions. Academy of Management Journal, 32, 115-130.

Giles, W. F., Findley, H. M., \& Feild, H. S. (1997). Procedural fairness in performance appraisal: Beyond the review session. Journal of Business and Psychology, 11(4), 493-506.

Goldberg, L. R., Johnson, J. A., Eber, H. W., Hogan, R., Ashton, M. C., Cloninger, C. R., \& Gough, H. G. (2006). The internationality personality item pool and the future of public domain personality measures. Journal of Research in Personality, 40, 84-86.

Greenberg, J. (1986). Organizational performance appraisal procedures: What makes them fair? In R. J. Lewicki, B. H. Sheppard \& M. H. Bazerman (Eds.) Research on negotiations in organizations: Volume 1, 25-41, Greenwich: JAI Press.

Greenberg, J. (1990). Organizational justice: Yesterday, today, and tomorrow. Journal of Management, 16, 399-432.

Ho, J. T. S., Ang, C. E., \& Ng, I. (1998). A preliminary study of kiasu behavior-Is it unique to Singapore? Journal of Managerial Psychology, 13(5/6), 359-370.

Horney, K. (1937). The neurotic personality of our time. New York: Norton.

Hwang, A. (2003). Adventure learning: Competitiveness (Kiasu) attitudes and teamwork. Journal of Management Development, 22(7/8), 562-578.

Hwang, A., Ang, S., \& Francesco, A. M. (2002). The silent Chinese: The influence of face and kiasuism on student feedback-seeking behaviors. Journal of Management Education, 26(1), 70-98.

Hwang, A. \& Arbaugh, J.B. (2006). Virtual and traditional feedback-seeking behaviors: Underlying competitive attitudes and consequent grade performance. Decision Sciences Journal of Innovative Education, 4(1), 1-28. 
IPIP. (2008). International Personality Item Pool: A Scientific Collaboratory* for the Development of Advanced Measures of Personality and Other Individual Differences. http://www.ipip.ori.org.

Kagda, S. (1993). Totally opposing traits. The Business Times, Executive Lifestyle, July $17,2$.

Kennedy, P. (2008). A guide to econometrics (6th ed.). Cambridge, MA: MIT Press.

Kohn, A. (1992). No contest: The case against competition (rev. ed.). Boston: Houghton Mifflin.

Kirby, E. G. \& Ross, J. K. (2007). Kiasu tendency and tactics: A study of their impact on task performance. Journal of Behavioral and Applied Management, 8(2), 108121.

Kline, T. J. B, Sulsky, L. M., \& Rever-Moriyama, S. D. (2000). Common method variance and specification errors: A practical approach to detection. The Journal of Psychology, 134(4), 401-421.

Kuncel, N. R., Crede, M., \& Thomas, L. L. (2005). The validity of self-reported grade point averages, class ranks, and test scores: A meta-analysis and review of the literature. Review of Educational Research, 75(1), 63-82.

Lee, K., Ashton, M. C., \& Shin, K. H. (2005). Personality correlates of workplace antisocial behavior. Applied Psychology: An International Journal, 54(1), 81-98.

Leo, D. (1995). Kiasu, kiasi: You think what? Singapore: Times Books International.

Leventhal, G. S. (1980). What should be done with equity theory? New approaches to the study of fairness in social relationships. In K. J. Gergen, M. S. Greenberg \& R. H. Willis (Eds.) Social exchange: Advances in theory and research, (pp. 2255), New York: Plenum Press.

McCabe, D. L., Butterfield, K. D., \& Trevino, L. K. (2006). Academic dishonesty in graduate business programs: Prevalence, causes, and proposed action. Academy of Management Learning \& Education, 5(3), 294-305.

McFarlin, D. B., \& Sweeny, P. D. (1992). Distributive and procedural justice as predictors of satisfaction with personal and organizational outcomes. Academy of Management Journal, 35, 626-637.

Morgan, L. A., \& Kunkel, S. (2007). Aging, Society, and the Life Cycle (3rd ed.). New York: Springer Publishing Company.

Mount, M. K., \& Barrick, M. R. (1995). The Big Five personality dimensions: Implications for research and practice in human resources management. In G.R. Ferris (Ed.), Research in personnel and human resources management (Vol. 13, pp. 153200). Greenwich, CT: JAI Press.

Murphy, K. R., \& Lee, S. L. (1994). Personality variables related to integrity test scores: The role of conscientiousness. Journal of Business and Psychology, 8(4), 413424.

Niederle, M. \& Vesterlund, L. (2007). Do women shy away from competition? Do men compete too much? The Quarterly Journal of Economics, 122(3), 1067-1101.

Nunnally, J. C., \& Bernstein, I. H. (1994). Psychometric theory (3rd ed.). New York: McGraw-Hill.

Pedhazur, E. L., \& Schmelkin, L. P. (1991). Measurement, design, and analysis: An integrated approach. Hillsdale, NJ: Erlbaum. 
Raviv, S., \& Netz, Y. (2007). Age, gender, and level of activity as moderators of personal incentives to physical activity in Israel. The Journal of Psychology, 141(3), 241-261.

Ross, S. R., Rausch, M. K., \& Canada, K. E. (2003). Competition and cooperation in the Five-Factor Model: Individual differences in achievement orientation. The Journal of Psychology, 137(4), 323-337.

Ryckman, R. M., Libby, C. R., van den Borne, B., Gold, J. A., \& Linder, M. A. (1997). Values of hypercompetitiveness and personal development in competitive individuals. Journal of Personality Assessment, 69, 271-283.

Salgado, J. F. (1997). The five factor model of personality and job performance in the European community. Journal of Applied Psychology, 82(1), 30-43.

Schwartz, B., Ward, A., Monterosso, J., Lyubomirsky, S., White, K., \& Lehman, D. R. (2002). Maximizing versus satisficing: Happiness is a matter of choice. Journal of Personality and Social Psychology, 83(5), 1178-1197.

Simon, H. A. (1955). A behavioral model of rational choice. The Quarterly Journal of Economics, 69(1), 99-118.

Spector, P. E., \& Brannick, M. T. (1995). The nature and effects of method variance in organizational research. In C.L. Cooper \& I.T. Robertson (Eds.), International review of industrial and organizational psychology (Vol. 10, pp. 249-274). Chichester, UK: Wiley.

Teng, C. I. (2008). Personality differences between online game players and nonplayers in a student sample. CyberPsychology \& Behavior, 11(2), 232-234.

Tepper, B. J. (1994). Investigation of general and program-specific attitudes toward corporate drug-testing policies. Journal of Applied Psychology, 3, 392-401.

Twenge, J. M. (2006). Generation Me: Why today's young Americans are more confident, assertive, entitled--and more miserable than ever before. New York: Free Press.

Tyler, T. R., \& Caine, A. (1981). The role of distributional and procedural fairness in the endorsement of formal leaders. Journal of Personality and Social Psychology, $41,642-655$. 